\title{
Intra-Abdominal Hemangioma
}

National Cancer Institute

\section{Source}

National Cancer Institute. Intra-Abdominal Hemangioma. NCI Thesaurus. Code C3635.

A hemangioma arising from organs within the abdominal cavity. 